\title{
Bladder Cancer Screening in Lebanese Population: There is Nothing more Unequal than the Equal Treatment of Unequal People
}

\author{
Mohammed Shahait and Muhammad Bulbul* \\ Urology Division, American University of Beirut Medical Center, Beirut, Lebanon
}

\begin{abstract}
Bladder cancer screening has been perplexing the uro-oncological community for the last decade. In this commentary, we ruminate on the feasibility of bladder cancer screening in our population based on epidemiological proponents.
\end{abstract}

The incidence of bladder cancer varies among different countries. According to the Globocan database 2012, Lebanon has the second highest incidence of bladder cancer after Belgium [1]. Moreover, Shamseddine et al. reported on the trends of different cancers in Lebanon, and the anticipated increase in the incidence of bladder cancer to reach 41.2 ASR in Lebanese men by 2018 [2].

The high incidence of bladder cancer among Lebanese can be attributed to high prevalence of smoking including water pipe smoking, and genetic predisposition [3].

In 2010, WHO estimated that about $42 \%$ and $28 \%$ of men and women smoked in Lebanon, respectively. In the WHO report about tobacco use, the projected trend of smoking in Lebanon is worrisome as it projects the rate to be approximately $57 \%$ for men and $39 \%$ for women [4]. Secondary analysis of the Global Youth Tobacco Survey (aged 13-15 years) measured that past-30 day water pipe tobacco use is highest in Lebanon (37\%) compared to 24 other Eastern Mediterranean and Eastern European Countries [5].

NAT1 is the main NAT expressed in bladder epithelial and cuboidal epithelium of proximal convoluted

\footnotetext{
*Correspondence to: Muhammad Bulbul, Urology Division, American University of Beirut Medical Center, Beirut, Lebanon. E-mail: mb30@aub.edu.lb.
}

tubules in the kidney. NAT $1 * 14 \mathrm{~A}$ has been reported to produce a slow acetylation phenotype; thus has been linked to increasing risk of bladder cancer. The frequency of NAT $1 * 14 \mathrm{~A}$ has been reported to be the highest in Lebanese people compared to other ethnicities [6]. Yassine et al. conducted an elegant case-control study to assess the effects of NAT1 genetic polymorphism on bladder cancer risk among Lebanese men. The authors found that patients with bladder cancer have significantly higher clustering of NAT1*14A compared to control [7].

Screening for breast cancer, colon cancer and, more recently, lung cancer has gained acceptance. However, screening for bladder cancer has not been adopted yet. This is partly due to the lack of diseasespecific symptoms. Adding to that, a large number of bladder cancer cases has an indolent course.

There are a scant number of studies that have been conducted reporting on the screening of bladder cancer. All these studies have screened populations with high-risk factors for developing bladder cancer.

Madeb et al. reported on the usefulness of using home urine dipstick as a screening test in detecting bladder cancer at an earlier stage and improving the survival outcome of the screened population [8]. In addition to the urine dipstick and urine cytology, another group incorporated urine biomarkers (NMP22, Urovysion) to improve the sensitivity of 
bladder tumor detection. The authors concluded that using this panel test as a screening tool for patients with a history of smoking of $\geq 40$ pack-years enabled detection of malignancy in $3.3 \%$ of this population [9].

The ideal screening test should be safe, cheap, non-invasive, and cost-effective. However, the gold standard test to diagnose bladder cancer is cystoscopy; which is not practical to screen asymptomatic individuals because of the invasive nature of the procedure and related expenses. On the other hand, there are a plethora of molecular markers that have been developed in the last decade (NMP22, BTA, Survivin, BLCA-4, DD23, uCyt+, UroVysion), all these markers have been studied extensively in disease diagnosis among symptomatic patients, or have been part of the surveillance of bladder cancer patients. Unfortunately, none of these markers is available in Lebanon.

It is very hard to draw a conclusion on the utility of any of these markers in screening from the available literature, because the performance of these markers depends on disease prevalence in the population.

Lotan et al. using Markov model to estimate cumulative cancer-related costs and the efficacy of screening of a high-risk population for bladder cancer, demonstrated an improvement in the overall survival in addition to cost saving if the cancer incidence is $>1.6 \%[10]$.

In summary, there is emerging evidence of the benefit of bladder cancer screening in highly selected populations. However, these studies were conducted in developed countries with low incidence of bladder cancer, and this may play a major role in disparaging the value of bladder cancer screening program. Amid the debate of the importance of bladder cancer screening, it is a praiseworthy argument that screening of our population might show unparalleled results contingent upon the high figure of disease occurrence in Lebanon.

\section{REFERENCES}

[1] Antoni S, Ferlay J, Soerjomataram I, Znaor A, Jemal A, Bray F. Bladder cancer incidence and mortality: A global overview and recent trends. Eur Urol 2016.

[2] Shamseddine A, Saleh A, Charafeddine M, Seoud M, Mukherji D, Temraz S, Sibai AM. Cancer trends in Lebanon: A review of incidence rates for the period of 2003-2008 and projections until 2018. Popul Health Metr 2014;12(1):4.

[3] Kobeissi LH, Yassine IA, Jabbour ME, Moussa MA, Dhaini HR. Urinary bladder cancer risk factors: A Lebanese casecontrol study. Asian Pac J Cancer Prev 2013;14(5):3205-11.

[4] World Health Organization. WHO global report on trends in prevalence of tobacco smoking 2015. World Health Organization; 2015.

[5] Jawad M, Lee JT, Millett C. Waterpipe tobacco smoking prevalence and correlates in 25 eastern mediterranean and eastern European countries: Cross-sectional analysis of the global youth tobacco survey. Nicotine Tob Res 2016;18(4):395-402.

[6] Dhaini HR, Levy GN. Arylamine N-acetyltransferase 1 (NAT1) genotypes in a Lebanese population. Pharmacogenetics 2000;10(1):79-83.

[7] Yassine IA, Kobeissi L, Jabbour ME, Dhaini HR. $\mathrm{N}$-acetyltransferase 1 (NAT1) genotype: A risk factor for urinary bladder cancer in a Lebanese population. J Oncol 2012;2012:512976.

[8] Madeb R, Messing EM. Long-term outcome of home dipstick testing for hematuria. World J Urol 2008;26(1):19-24.

[9] Steiner H, Bergmeister M, Verdorfer I, Granig T, Mikuz G, Bartsch G, Stoehr B,Brunner A. Early results of bladdercancer screening in a high-risk population of heavy smokers. BJU Int 2008;102(3):291-6.

[10] Lotan Y, Svatek RS, Sagalowsky AI. Should we screen for bladder cancer in a high-risk population?: A cost per lifeyear saved analysis. Cancer 2006;107(5):982-90. 